\title{
ON THE (PSEUDO) CAPACITIVE PERFORMANCE OF JACK FRUIT SEED CARBON
}

\author{
Palanichamy Kalyani $^{1 *}$, Ariharaputhiran Anitha ${ }^{2}$ \\ ${ }^{1 *}$ Department of Chemistry, Madurai Kamaraj University, Madurai 625 021, India \\ ${ }^{2}$ Department of Chemistry, SACS MAVMM Engineering College, Madurai 625 301, India
}

\begin{abstract}
Today, the idea of utilizing biomass from agricultural wastes as a raw material for producing (activated) carbons has attracted the interest of researchers worldwide for the obvious multifarious applications of carbon. As a novel attempt, carbon has been derived from a domestic biomass waste viz., the jack fruit seeds (Artocarpus heterophyllus) and tested its prospects as electrodes in energy storage devices namely electrochemical capacitors. Jack Fruit Seed Carbon (JFSC) is produced by simply pyrolyzing JFS under $\mathrm{N}_{2}$ atmosphere without making use of any activating agents. Capacitive behavior in $1 \mathrm{M} \mathrm{H}_{2} \mathrm{SO}_{4}$ \& $1 M \mathrm{Na}_{2} \mathrm{SO}_{4}$ electrolytes are evaluated by impedance spectroscopy, cyclic voltammetry and galvanostatic charge-discharge studies. $\mathrm{N}_{2}$ sorption studies evince the presence of microporous nature of the JFSC. Cyclic voltammetry estimates specific capacitance as high as 316 and $203 \mathrm{Fg}^{-1}$ respectively in $\mathrm{H}_{2} \mathrm{SO}_{4}$ and $\mathrm{Na}_{2} \mathrm{SO}_{4}$ at a scan rate of $10 \mathrm{mVs} \mathrm{s}^{-1}$. JFSC show excellent electrochemical cycle stability in $1 \mathrm{M} \mathrm{H}_{2} \mathrm{SO}_{4}$ with $93 \%$ of the initial capacitance being retained at the end of $500^{\text {th }}$ cycles. The studies infer that JFSC has immense potential as an electrode material in electrochemical capacitors while its performance largely depends upon physical features, surface functional groups or the hetero atoms contributing pseudocapacitive nature to the JFSC. Thus the work not only describes a waste utilization scheme but also presents a new and valuable dimension to the usefulness of jack fruit seeds in electrochemical capacitors
\end{abstract}

Keywords: Electrochemical capacitors; Pseudocapacitors, Biomass Carbon electrode and Jack Fruit seeds $* * *$

\section{INTRODUCTION}

Electrochemical capacitors are attractive energy storage devices owing to its long cycle life, high efficiency, high power density and eco-friendliness. Specifically, pseudocapacitors store energy in two ways: (a) by capacitive charging of the double layers of the electrodes i.e. energy is stored electrostatically in proportion to the area of the double layers and (b) through the products of Faradaic (eg. redox) reactions at the electrode surfaces i.e. energy is stored electrochemically. The capacitance due to the former is called electric double layer capacitance and the latter is called pseudo-capacitance. Whatever the instance may be, selection of appropriate electrode and electrolyte are the fundamental factors in determining the overall capacitor performance. Thus exploding research is being conducted to engineer novel materials for lowering the costs of the capacitors for various projected applications and for realizing in the commercial energy front.

The prospective electrode materials for electrochemical capacitors are carbon [1-7], the reasons being its abundance, lower cost, easy processing, non-toxicity, higher specific surface area, good electronic conductivity, high chemical stability, and wide operating temperature range [8]. High surface area carbon materials mainly include activated carbon [9-14], carbon aerogels [15], CNTs [16, 17], templated porous carbons [18-21], and carbon nanofibres [22]. Normally carbon materials with larger specific surface

*Corresponding author: P. Kalyani

Email id: kalyani_1973@yahoo.com areas have a higher capability for charge accumulation at the electrified interface, rather than in bulk of the capacitive material. Therefore, the capacitance predominantly depends on the surface area of the electrode accessible to the electrolyte ions so that activated carbons with a large surface area are generally preferred. On the other hand, due to the contact resistance between carbon particles resistivity of the carbon particles will increase resulting in a high internal series resistance with an ultimate reduction in electrochemical performance [8]. In addition to the above fact, the electrode surface area inaccessible to electrolyte ions [23] also impedes the capacitance performance of carbon materials, resulting in limited capacitance. Further, all micropores in the electrode may not necessarily be accessible to electrolyte ions. Hence sometimes specific capacitance may not be directly proportional to the surface area. So in order to off-set these effects researchers employ pseudocapacitive electrode materials to realize improved specific capacitance.

Pseudo-capacitive materials reported in the literature mostly are conducting polymers and electroactive metal oxides [24]. These reports stress that carbonaceous materials with surfacial organic functional groups or heteroatoms would be a choice for electrode materials and that the hetero-groups help the adsorption of the electrolytes ions thereby improving the hydrophilicity or lipophilicity, wettability and rapid electrolyte ions transport within the micropores of the carbon materials [25]. Carbons with heteroatoms like oxygen and nitrogen would induce Faradaic redox reactions leading to a $5-10 \%$ increase in the total capacitance when 
compared with carbon containing no heteroatoms [26]. Recently Leitner et al. reported a nitrogen-containing carbon material with high pseudo-capacitance even in the absence of substantial surface area [27]. Faradaic redox reactions exhibited by carbon materials containing nitrogen are extensively studied for the capacitors applications by many researchers over the globe [28-31].

The presence and the amount of functional groups containing oxygen, such as $-\mathrm{COOH}$ and $\mathrm{C}=\mathrm{O}$, depends mainly on the precursors used and preparation conditions for deriving the carbon powders. It is well known that these functional groups are acidic and electrochemically active too that contributes to the pseudo-capacitance by large [32]. The article by Jurewicz et al. [28] with six activated carbon samples with $S_{B E T}=1156-2571 \mathrm{~m}^{2} \mathrm{~g}^{-1}$ stresses the importance of the surface groups towards achieving pseudocapacitance. It is interesting to observe that oxygen atoms on the surface has ill-effects like self-discharge, leakage current, only in non-aqueous electrolytes, whereas in aqueous electrolytes especially in $\mathrm{H}_{2} \mathrm{SO}_{4}$ solution, the total capacitance increases due to pseudo-capacitance.

Pseudocapacitance credited with Faradaic reactions of oxygen-containing functional groups with electrolyte ions is identical with the capacitance developed by Faradaic materials like transition metal oxides, such as $\mathrm{RuO}_{2}$ and $\mathrm{MnO}_{2}$ [24]. Thus, carbons with surface functional groups or heteroatoms appear to be cost-effective alternative electrode materials. Consequently, materials of vegetable origin has thus been given importance as they contain appreciable amount of carbon and would offer high valued scientific, industrial and engineering product namely carbon (with heteroatoms) through the carbonization of these zero-cost biomass. Sometimes the utilization of biomass wastes also provides a solution for waste disposal.

Survey of recent research reports shows that carbon materials derived from biomass has the potential of being utilized as electrode materials in electrochemical capacitors [33-40]. Hence, the purpose of this study is to examine the feasibility of obtaining carbon from a common domestic vegetable waste viz., the Jack Fruit Seeds (JFS) and to completely evaluate the applicability of the obtained carbon as an electrode material for electrochemical capacitor (pseudocapacitors) in acid as well as neutral medium. Jack fruit is consumed as such or can form an important ingredient in jellies, jams, salads and other delicious sweets. The seeds of jack fruit also have food value which contains glucose and proteins and are used in many varieties of food stuffs. Even so the seeds are discarded from most of the houses and food processing units. On the other side our attention focussed on utilizing the excess or unused seeds to show their potential in industrial and scientific applications as electrode materials. It is an interesting fact that jack fruit seeds can serve as a cheap raw material source for carbon for electrodes in capacitors and further upgradation of vegetable wastes to valuable energy can be realized.
To best of our knowledge the use of jack fruit seeds for obtaining carbon has never been attempted. Nevertheless, it is interesting and valuable to note that Prahas et al. [41] had made use of jack fruit peel to derive activated carbon for adsorbing methylene blue dye and have explored the pore structures and surface chemistry in detail [42]. Kannan et al. [43] used carbon derived from JFS as an alternative adsorbent to commercial activated carbon for effluent treatment, especially for the removal of cadmium (II) ions. Further, Tamez et al. [44] applied jack leaf powder as an adsorbent for methylene blue removal. All the above investigations reveal that biomass offers multifarious applications in one or the other advanced technologies. Thus in the present work we have explored the physical features of the jack fruit seed derived carbon and have evaluated the capacitive nature in acid and neutral electrolyte medium to establish the usefulness of the discarded jack fruit seeds in the area of capacitors.

\section{EXPERIMENTAL}

\subsection{Preparation of JFSC}

Seeds from a ripe jack fruit were collected from the farm house of one of the authors, located at Madurai and washed several times with hot de-ionized water after which the white outer cover (arils) as well as the brown colored inner seed coat (spermoderm) were peeled off with a little hand pressure. The seeds were finally washed with de-ionized water and diced ( $5 \mathrm{~mm}$ thick). The pieces were pat dried with wet tissue paper and $\sim 10 \mathrm{~g}$ sample was immediately pyrolized under flowing nitrogen at $500{ }^{\circ} \mathrm{C}$ at a heating ramp of $5{ }^{\circ} \mathrm{C} / \mathrm{min}$ for a hold period of 1 hour, furnace cooled to give a mass of char. Peled et al. [45] have observed that larger sample size may lead to abundant pyrolysis products which may attack the newly formed carbon surface, causing an increase in the surface area and destruction of the carbon bulk. This may have bad effects on the electrochemistry of the carbon powders. The authors of the present investigation also agree with this fact and hence took an optimum size of $10 \mathrm{~g}$ of the raw material. The char was finally washed with hot de-ionized water until the $\mathrm{pH}$ of the decant solution was approximately 7 . The powder so obtained after drying and grinding is hereafter called JFSC. Finally JFSC powder was sieved to 250 mesh size and used for further studies.

\subsection{Physico-Chemical Characterization}

$\mathrm{X}$-ray diffraction patterns were recorded between 10 to $80^{\circ}$ on X'Pert Pro X-ray diffractometer with $\mathrm{CuK}_{\alpha}$ radiation source. The specific surface functional groups on the surface of the biomass carbon were ascertained using FT-IR spectrometer (Model \# Nexus 670) in the range from 4000 $\mathrm{cm}^{-1}$ to $400 \mathrm{~cm}^{-1}$. Elemental analysis of the JFSC was done by Vario ELIII CHNS/O elemental analyzer. The morphology of the carbon was examined with Hitachi S4700 , field emission scanning electron microscope. The pore structure of the JFSC was characterized by $\mathrm{N}_{2}$ adsorption at $77 \mathrm{~K}$ using Micromeritics ASAP 2020 instrument 
(Micromeritics, USA). Surface area of the JFSC powder was determined by BET (Brunauer, Emmet and Teller) method.

\subsection{Electrode Preparation and Electrochemical}

\section{Measurements}

JFSC, poly vinylidene fluoride binder and carbon black respectively in the weight ratio $85: 10: 5$ were mixed to get a paste using N-methyl 2 pyrrolidone. The paste was applied on to the circular end of an SS rod of $1 \mathrm{~cm}^{2}$ area \& length $8 \mathrm{~cm}$. The electrode was dried at $80{ }^{\circ} \mathrm{C}$ for 1 hour. Heat shrinkable sleeve was used to mask rest of the electrode portion. Electrochemical studies (Impendance, Cyclic Voltammetric (CV) and galvanostatic charge-discharge) were performed with CH Instruments (Model \# CHI660a) in a three-electrode configuration using the SS rod coated with JFSC as the working electrode, Pt wire as the counter, and saturated calomel electrode as the reference. $1 \mathrm{M} \mathrm{H}_{2} \mathrm{SO}_{4}$ \& $1 \mathrm{M} \mathrm{Na}_{2} \mathrm{SO}_{4}$ were employed as the electrolytes. The specific capacitance was evaluated from the area of the $\mathrm{CV}$ curves. Galvanostatic charge discharge experiments were performed in a similar setup as described above with a specific current density of $10 \mathrm{mAg}^{-1}$ and between 0.0 and $1.0 \mathrm{~V}$. AC impedance measurements were taken with a superimposing AC voltage of $5 \mathrm{mV}$ within a frequency range of $1 \mathrm{mHz}-$ $100 \mathrm{kHz}$.

\section{RESULTS AND DISCUSSION}

\subsection{Burn-off}

Conversion of JFS biomass in to carbon was carried out around $500{ }^{\circ} \mathrm{C}$ under flowing $\mathrm{N}_{2}$ and weighed the residue to calculate the yield otherwise termed as burn-off. Burn-off was calculated by applying the following formula [46] and was found to be $76 \%$ on dry basis. $X(\%)=\left(\mathrm{m} / \mathrm{m}_{\mathrm{o}}\right) \times 100$, where $\mathrm{X}$ is carbon yield $(\%), \mathrm{m}$ is the carbon mass $(\mathrm{g})$ and $\mathrm{m}_{\mathrm{o}}$ is the raw sample mass $(\mathrm{g})$.

It can thus be concluded that JFS can give high $\%$ yield of carbon. The reason for high $\%$ yield may be due to the thermal processing of the samples under controlled atmosphere where oxygen is inaccessible to prevent the transformation of hetero elements in to their corresponding oxide gases or even ash. Nonetheless, it will be proved from the FT-IR spectroscopic studies (or ultimate elemental analysis) that organic groups are still present in the carbon structures to play a part in the electrochemical features of the carbon samples derived from JFS.

\subsection{Ultimate Analysis}

The biomass derived carbon samples consists principally of carbon atoms (which form aromatic sheets cross-linked in a random manner) and heteroatoms like oxygen, nitrogen, sulphur, hydrogen depending on the nature and source of the raw material considered and obviously on the thermal, physical or chemicals treatments [47]. Consequently the type and $\%$ of the constituents is expected to influence the electrochemical parameters and hence ultimate elemental analysis has been conducted on the JFSC. Added to the above, it is well known that the heating rate controls the rate of volatile evolution from the biomass during pyrolysis and so slow heating and longer volatile times would promote high char yield [48]. This fact is obvious in the present work that the pyrolysis of JFS yielded a mass that was analyzed to contain $71.4 \mathrm{wt} \%$ carbon with certain amount of $\mathrm{H}$ $(1.476 \%), \mathrm{S}(0.836 \%)$ and $\mathrm{N}(3.821 \%)$ also existing in the JFSC, but the total amount of these elements in weight is less than $100 \%$. On the basis of previous reports about thermally-treated carbon material, the remaining component of the carbon material should be oxygen [49, 50]. Significant \% of N, S \& H in the sample shows the presence of various organic functional groups. FTIR data also bears support for these organic functional groups, the presence of which is expected to influence the electrochemical behavior of the carbon samples prepared as discussed in the latter sections.

\subsection{Phase analysis by X-ray Diffractometry (XRD)}

The XRD pattern of the biomass carbon is shown in Fig. 1. The presence of a strong peak between $23^{\circ}$ and $30^{\circ}$ is definitely attributed to (002) diffraction peak, indicating the amorphous and low graphitization features of the carbon produced from JFS. The nature of the peak may also indicate the evolution of microporous carbon and the microporous structure is amorphous with enormous degree of non-crystalline signatures [51]. Concisely, a large number of disordered single graphene layers and stacked structures of graphene sheets may be present simultaneously in the texture of the carbon powder [52] and the slightly broad shape also indicates the highly disordered structure in the carbon [53]. It is to be noted that the interplanar space $\left(d_{002}\right)$ calculated for the JFSC is $3.78 \AA$, higher than that reported for graphite $(3.354 \AA)$ again indicating considerable disorderliness in the carbon produced [54-56].

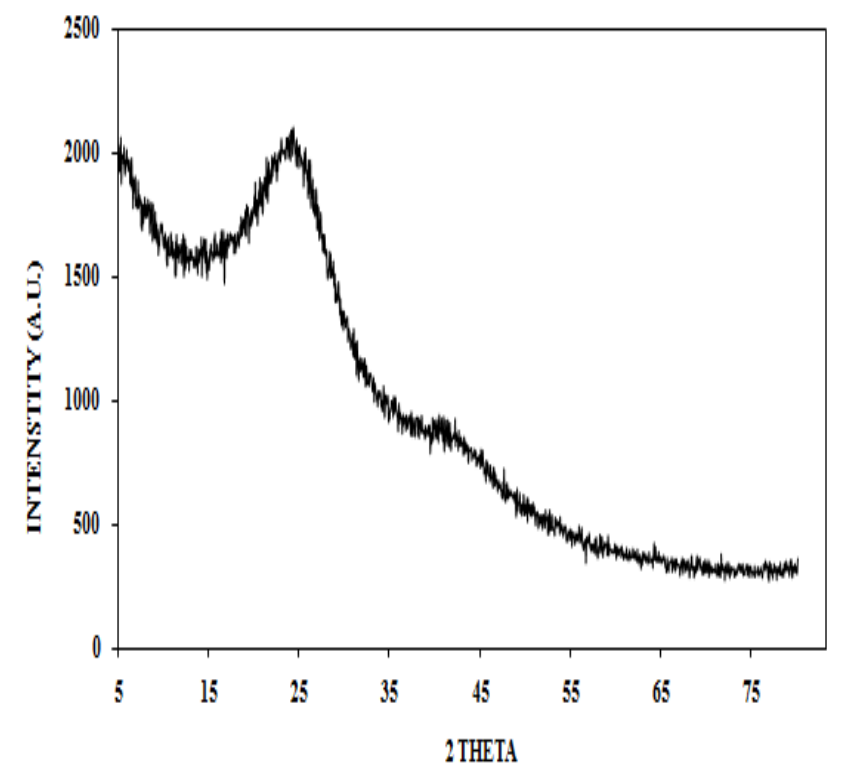

Fig 1 X-ray diffractogram of JFSC

Generally the value of $\mathrm{d}_{002}$ is taken as a measure of estimating the degree of graphitization in the carbon and the 
growing disorder is now reflected in the observed larger values of $d_{002}$ in JFSC. The XRD of the JFSC at the same time exhibits a broad peak around $43^{\circ}$ and has been attributed to the $\left(\begin{array}{ll}1 & 0\end{array}\right)$ bidimensional planes [57]. The existence of $h k\left(\begin{array}{ll}1 & 0\end{array}\right)$ lines may be an evidence for the turbostatic or convoluted stacking of hexagonal layers of carbon resulting in disordered structure and lower crystallinity $[58,59]$ thus demonstrating amorphous nature of the JFSC and hence better capacitance may be expected.

\subsection{Scanning Electron Microscopic (SEM) Imaging,}

\section{Pore Structure and Surface Area Measurements}

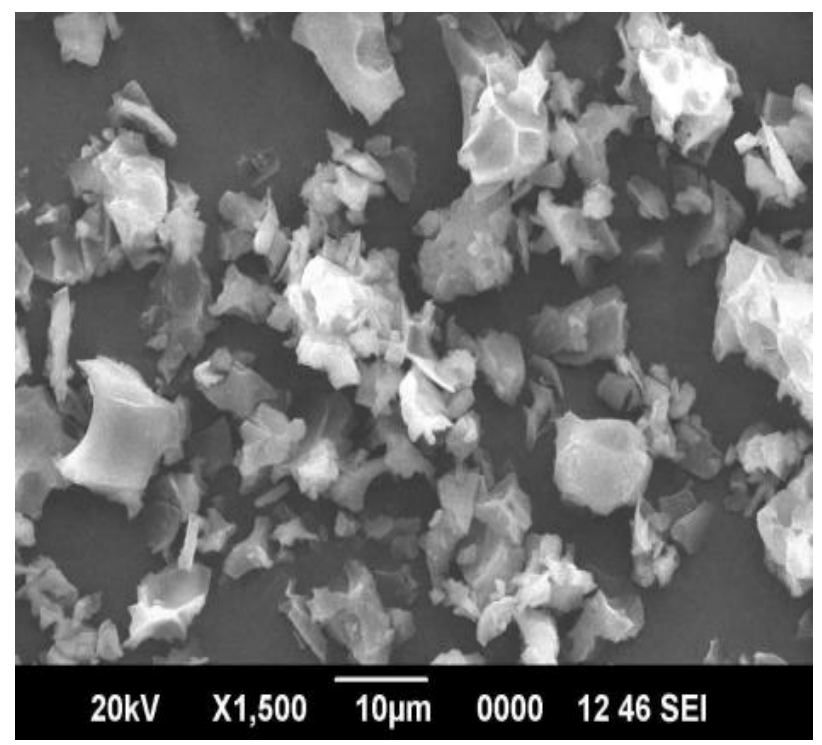

Fig 2 SEM image of JFSC

Fig. 2. depicts the SEM of JFSC. The micrograph shows a loose, disjointed structure with carbon particles of irregular size and ununiform distribution featuring crumbled/crushed morphology, entirely lacking porosity. This peculiar morphology may be due to the force of the gases escaping from the biomass during the pyrolysis process [60]. It is now rather difficult to offer any correlation between the particle morphology and the electrochemical activity. Regardless of this fact, the pore structure of the JFSC was characterized by $\mathrm{N}_{2}$ adsorption and the isotherm has been presented in Fig. 3 . It is to be mentioned that the carbonization process enriches the carbon content with concomitant removal of volatile matters which may create the initial porosity in the biomass carbon. The isotherm was found to be the type-1 characteristic, with a broad knee within low relative pressure range [61], reflecting the high microporosity in the sample. In general, microporous solids generally show Type-I adsorption isotherms [62]. $\mathrm{N}_{2}$ adsorption isotherm curve features a plateau indicating that the adsorption might have been stopped. The quick saturation of $\mathrm{N}_{2}$ adsorption in fact is due to proximity of the pore walls such that the multilayers of $\mathrm{N}_{2}$ would not be formed. This result means that the sample would not be containing large numbers of mesoporous or macroporous structures and only micropores.

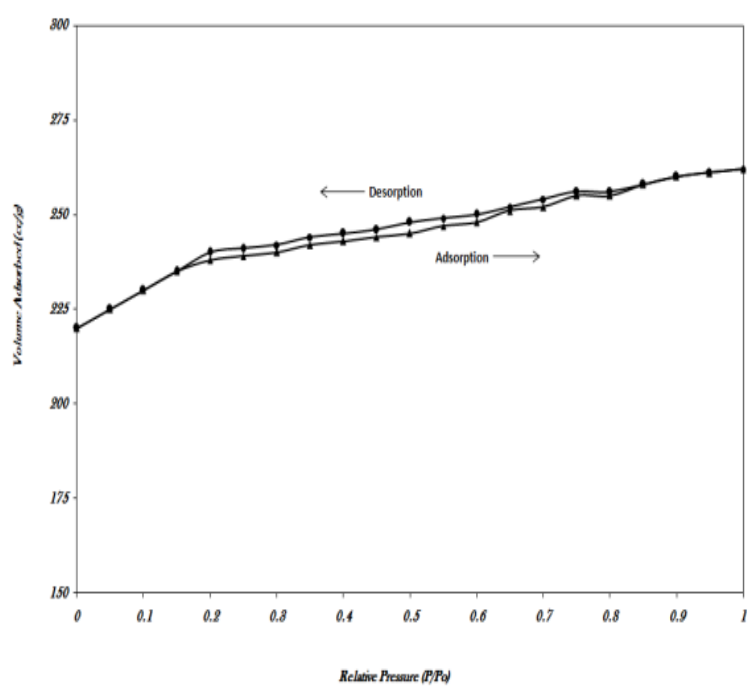

Fig $3 \mathrm{~N}_{2}$ sorption isotherm of JFSC powder

BET surface area of JFSC calculated using BET equation is $932 \mathrm{~m}^{2} \mathrm{~g}^{-1}$ having micropore and mesopore surface area of $898 \mathrm{~m}^{2} \mathrm{~g}^{-1}$ and $34 \mathrm{~m}^{2} \mathrm{~g}^{-1}$ respectively. The total pore volume of carbon measured at relative pressure of 0.995 is $0.51 \mathrm{~cm}^{3} \mathrm{~g}^{-1}$ whereas micropore and mesopore volumes are of 0.46 and $0.05 \mathrm{~cm}^{3} \mathrm{~g}^{-1}$ respectively. Micropore volume accounts for $90 \%$ of total pore volume, which has its proof in the adsorption isotherm curve. Surface area of the JFSC seem to lie within the range of many biomass derived activated carbons reported and this high value of the surface area may probably indicate the presence of enormous electrochemically accessible sites or area thereby resulting in increased electrochemical performance ultimately, which will be made obvious from the discussions made under electrochemical studies section.

\subsection{Functional Group Analysis or Surface Chemistry Characterization Studies}

The carbon matrix of JFSC contains heteroatoms like, oxygen, nitrogen, sulfur etc., besides carbon and hydrogen atoms. These heteroatoms bonded to the edges of the carbon layers govern the surface chemistry of the carbon [63]. The surface chemistry of carbon materials is basically determined by the acidity and basicity of their surface. The existence of surface functional groups such as carboxyl, lactone, phenol, carboxylic anhydride, etc., may constitute the source of surface acidity, while the basic properties of the carbon may likely be associated with two types of structures: (i) the presence of oxygen containing groups, i.e. pyrone, chromene and carbonyl structures, at the edge of carbon crystallite; and (ii) oxygen free Lewis basic site on the graphene layers. The Lewis basicity of delocalized $\pi$ electrons is influenced by the aromatic system on the carbon surface as stipulated by Wibowo et al. [63].

Electrochemical features of carbon electrode material seem to depend upon the physical properties as well as the nature and chemical reactivity of the functional groups that may be present on the carbon surface. Accordingly, gaining knowledge on surface functional groups would give us a 
chance of correlating with the electrochemical properties of the carbon. FTIR spectroscopy is a technique for qualitative characterization of the surface functional groups on the carbon samples. Fig. 4 depicts the FTIR spectrum of JFSC. The spectrum shows highly complex signatures, which is due to the presence of many polar functional groups on their surface. These organic, especially oxygen containing functionalities may help in imparting hydrophilicity to the carbon electrode that favors strong interaction of the aqueous electrolyte ions with the polar groups in the carbon material and thus plays an important role for the performance of a capacitor [64].

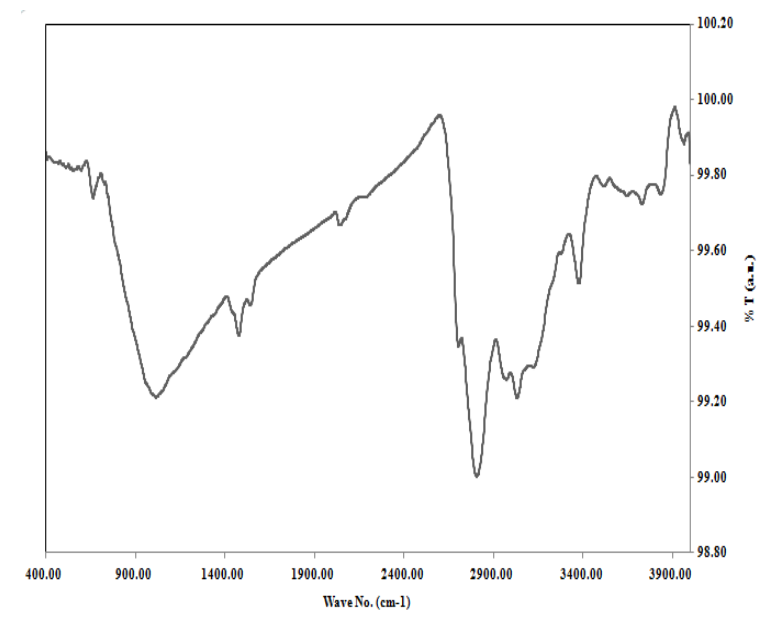

Fig. 4 FT-IR of JSFC powder

The spectrum obtained for JFSC sample shows the characteristic peak at $3388 \mathrm{~cm}^{-1}$ corresponding to the $\mathrm{O}-\mathrm{H}$ stretching vibration of the surface hydroxyl groups. The peak around $2923 \mathrm{~cm}^{-1}$ and $671 \mathrm{~cm}^{-1}$ in the sample indicates the presence of aliphatic $\mathrm{C}-\mathrm{H}$ bond and $\mathrm{C}-\mathrm{C}$ bond respectively corresponding to the methylene group. A characteristic peak observed at $1595 \mathrm{~cm}^{-1}$ corresponding to $\mathrm{C}=\mathrm{O}$ (carbonyl) stretching vibration in quinone structure. In addition, the isolated $-\mathrm{OH}$ functional group is observed at $3737 \mathrm{~cm}^{-1}$ for the sample. On the other hand, characteristic peak at $1367 \mathrm{~cm}^{-1}$ corresponding to the stretching mode of $\mathrm{C}=\mathrm{N}$ group and the peak around $1024 \mathrm{~cm}^{-1}$ corresponds to $\mathrm{C}-\mathrm{O}$ bond in alcohol. From this study it could be inferred that the surface of the JFSC might contain carbonyl and/or quinone type groups. A medium intense band around $3400-$ $3500 \mathrm{~cm}^{-1}$ may be attributed to the stretching mode of $\mathrm{N}-\mathrm{H}$ group.

Organic groups with oxygen, typically, phenols, carbonyls, lactones, quinone and quinone-like structures are expected to form on the surface during the thermal treatment of the biomass precursors and may appear at the edge carbon atoms as indicated by Subramanian et al. [36]. This fact may also be applied to JFSC samples and the effect or mechanism of action of these organics on the electroactivity of the carbon samples may be complex and forms an exclusive research object. Centeno and Stoeckli [64] have reported that oxygen containing functionalities impart good features to the performance of the carbons and hence comparatively acceptable electrochemical behavior may be expected from JFSC. The influence of organic groups $\mathrm{H}, \mathrm{N}$, $\mathrm{O}$ on the electrochemical performance may be important but it is difficult to explain the electrochemical behavior because we do not know the exact location of these elements in the carbon structures where these groups undergo electrochemical transformation under the influence of electrical signal during electrochemical studies or chemical reactions with the electrolyte species.

\subsection{Effects of Electrolytes on the Capacitive}

\section{Behavior of JFSC as Evaluated from Impedance}

\section{Data}

The frequency dependence of the impedance of the JFSC has been studied through Electrochemical Impedance Spectroscopy at a bias voltage of $5 \mathrm{mV}$ between $1 \mathrm{mHz}$ and $100 \mathrm{kHz}$ using the three electrode assembly in two different electrolyte medium. The electrochemical impedance studies conducted on the JFSC electrodes in the two electrolytes are compared in Fig. 5 as Nyquist plots. The data was fit based on Randles equivalent circuit and various parameters include $\mathrm{C}_{\mathrm{dl}}$ derived are given in Table 1 .

It is well known that the impedance of an ideal capacitor has no real component and its imaginary component is a function of both capacitance and frequency. The current through a capacitor is always $90^{\circ}$ out of phase with the voltage across it and current leading the voltage. Because the impedance of a capacitor varies inversely with frequency, at high frequencies a capacitor acts as a short circuit - its impedance tends towards zero. At low frequencies (approaching DC) a capacitor acts as an open circuit, and the impedance tends towards infinite. So for an ideal EDLC the imaginary part of the impedance spectra at lower frequencies would be a vertical line and the impedance of a capacitor diminishes as the frequency Increases. The observed impedance of electrodes fabricated using JFSC in the high frequency region is mainly contributed by the total resistance that includes contribution from the solution resistance $\left(R_{s}\right)$, intrinsic carbon resistance and constant phase element (CPE). $R_{s}$ is known as the ohmic or uncompensated resistance of the solution between the working and reference electrodes. Diffusion of electrolyte ions in to the electrode matrix can create impedance known as the Warburg impedance (W). This impedance depends on the frequency of the perturbing potential.

At high frequencies, the Warburg impedance is small since diffusing ions or reactants do not have to move very far. At low frequencies the reactants have to diffuse farther, thereby increasing the Warburg impedance. On a Nyquist plot the infinite Warburg impedance appears as a diagonal line with a slope of 0.5 (or $45^{\circ}$ in the Bode plot). Thus a vertical line in the low frequency region in the Nyquist plot indicates ionic diffusion process and the observed semicircle in the middle frequency range reveals the charge transfer resistance $\left(R_{c t}\right)$ or polarization resistance $\left(R_{p}\right)$. The amplitude and width (diameter) of the semicircle indicates 
the accessibility of active electrode surfaces due to factors such as pore shape, size, and the variations in pore distribution within the electrodes [65].

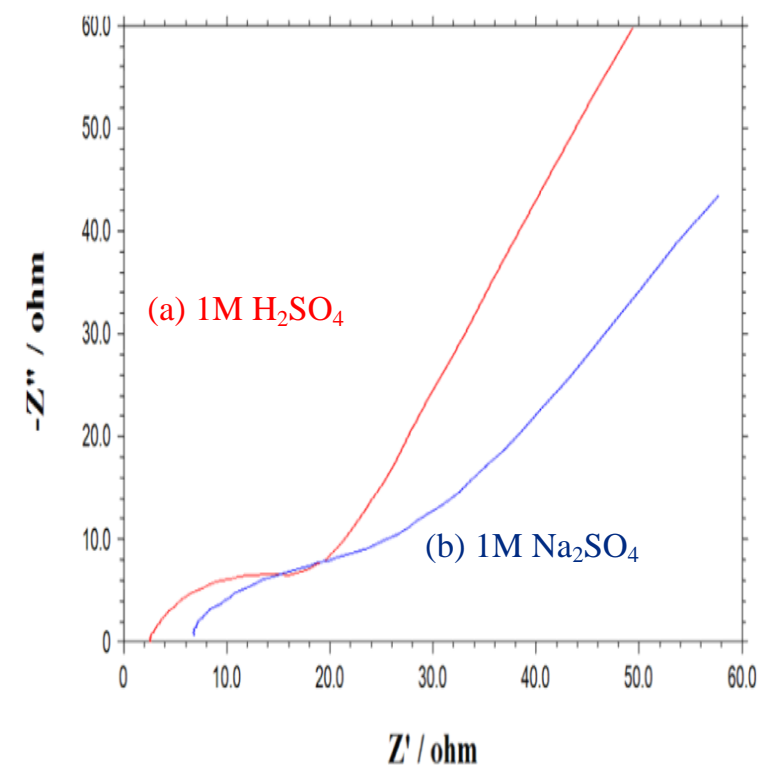

Fig 5 Nyquist AC impedance plots for JFSC electrode in (a) $1 \mathrm{M} \mathrm{H}_{2} \mathrm{SO}_{4}$ and (b) $1 \mathrm{M} \mathrm{Na}_{2} \mathrm{SO}_{4}$.

Obviously Fig. 5 features a $45^{\circ}$ Warburg region at low frequencies in the two electrolytes studied. This phenomenon hence is attributed to the diffusion of ions and hence an increase of electrolyte ions diffusion resistance is observed. The line in Fig. 5 depicts the capacitive nature of JFSC in the two electrolytes. The impedance plot also shows apparent semicircle corresponding to double layer charging at mid-high frequencies in the two electrolytes and this observation can be related to the charge transfer resistance. A larger single semi-circle in neutral medium indicates that charge transfer in carbon electrode is higher than that in the acid electrolyte. Furthermore, the knee frequency occurs much earlier in terms of both real and imaginary impedance components in acid compared with the neutral electrolyte, indicating the potential of JFSC as an electrode material in electrochemical capacitors, where its total impedance is the least in the former.

From the Nyquist plot, the specific capacitance of the JFSC electrode in the two electrolytes tabulated in Table 1 has been calculated using the formula [39]: $C=1 /(2 \pi \mathrm{fZ}$ "m $)$, where $\mathrm{f}, \mathrm{Z}$ " and $\mathrm{m}$ are the frequency $(1 \mathrm{mHz})$, the imaginary impedance and the mass of the JSFC in the electrode respectively. It is to be appreciated that the capacitance values from the impedance studies are comparable with those calculated from $\mathrm{CV}$ studies and this result thus supports the observation made by Garcia-Gomez et al. [66] to corroborate the fact that the specific capacitance value evaluated from AC impedance studies would be comparable to that obtained from $\mathrm{CV}$ or charge-discharge studies provided the low frequency set in impedance studies, the sweep rate in $\mathrm{CV}$ studies and the current in charge-discharge studies are comparable enough.
Table 1 Analysis results of impedance spectroscopic data on JFSC

\begin{tabular}{|l|l|l|l|}
\hline $\begin{array}{l}\text { Electrolyte } \\
\text { medium }\end{array}$ & $\begin{array}{l}\mathbf{R}_{\text {s }} \\
(\mathbf{o h m})\end{array}$ & $\begin{array}{l}\mathbf{R}_{\text {ct }} \\
(\mathbf{o h m})\end{array}$ & $\begin{array}{l}\mathbf{C}_{\text {dl }} \\
(\mathbf{F} / \mathbf{g})\end{array}$ \\
\hline $1 \mathrm{M} \mathrm{H}_{2} \mathrm{SO}_{4}$ & 2.6 & 21.4 & 321 \\
\hline $1 \mathrm{M} \mathrm{Na}_{2} \mathrm{SO}_{4}$ & 6.8 & 24.2 & 212 \\
\hline
\end{tabular}

\subsection{Electrochemical Investigation by Cyclic}

\section{Voltammetric (CV) and Galvanostatic Charge-}

\section{Discharge Cycling Studies}

Capacitive behavior of the JFSC electrode has been explored through $\mathrm{CV}$ studies in the two electrolyte systems chosen. Further, the effects of scan rates have also been investigated. Accordingly, CVs have been recorded at scan rates from 10 to $40 \mathrm{mVs}^{-1}$ with increments of $10 \mathrm{mVs}^{-1}$ and the voltage window in each case is as marked in the $\mathrm{CV}$ illustrated in Fig. 6a and b respectively in $1 \mathrm{M} \mathrm{H}_{2} \mathrm{SO}_{4}$ and $1 \mathrm{M} \mathrm{Na}_{2} \mathrm{SO}_{4}$. The specific capacitance values have been calculated using the equation, $C=\mathrm{i} / \mathrm{sm}\left(\mathrm{Fg}^{-1}\right)$, where $\mathrm{i}$, s and $\mathrm{m}$ are the average current, the scan rate and the mass of the active material [67]. The authors of the present communication had reviewed more than 100 research articles describing the utility of biomass (wastes) for deriving carbons or activated carbons for the title subject to signify the waste to energy concept through utilization of wastes [68]. Reference to this review article had been made here to compare the capacitance values of the various biomass derived carbons in different electrolyte medium with our present studies using JFSC. Reports establishing the results of biomass derived carbon electrode materials for capacitors in neutral medium is rather less and to cite a few; banana fiber [36], fir wood [69] and pistachio shells [70] respectively in $\mathrm{NaNO}_{3}$, seaweed [71] in sodium sulphate solution, coconut shells [72] in $\mathrm{KCl}$ solution exhibited good capacitive nature. Analysis illustrates that extensive research with various other classes of neutral electrolyte medium is still open for obtaining capacitors with good performance.

The observed capacitive currents in $1 \mathrm{M} \mathrm{H}_{2} \mathrm{SO}_{4}$ is higher than in $1 \mathrm{M} \mathrm{Na}_{2} \mathrm{SO}_{4}$ and increase with the increase in scan rate but is not proportional to the square root of the scan rate. This implies that there would be redox transitions of various organic functionalities and the ultimate capacitance is of pseudocapacitive type. Hu et al. [70] and $\mathrm{Wu}$ et al. [72] in their studies with $\mathrm{KOH}$-activated pistachio shells and coconut shells respectively in acid and neutral electrolytes observed the current variation with respect to the type of electrolytes and they presumed to be due to the better conductivity of the acid by proton hopping mechanism [73] and also redox reactions (see later sections) at the carbon electrode. In the neutral medium the bigger electrolyte ions offer restricted ionic movements in the solution and hence lesser voltammetric currents are obtained. This fact is also supported by AC impedance studies, where $\log Z_{r e}$ and $R_{s}$ is higher in neutral medium than the acid electrolyte. 
The presence of heteroatoms and organic functional groups in JFSC would present pseudocapacitance nature to JFSC based electrode and this is apparent from the distorted rectangular shape of CVs, as seen in Fig. 6a and b. Further, non- linear current with increasing voltage is the characteristic feature observed in both the electrolytes, indicating the large Faradic nature of our JFSC electrodes. In general, $\mathrm{CVs}$ in the two electrolytes exhibit symmetric responses in their positive as well as negative scans and the integrated voltammetric charges in the positive and negative scans evolves to be closer. It can thus be concluded that the charges stored in the positive scans could be delivered during the negative scans and consequently good electrochemical behavior of the JFSC is indicated. It can also be noted that the current rapidly reach their respective plateau values when the scan is reversed. This demonstrates lower ESR of the JFSC electrode in the chosen electrolytes.

The CV in acid the electrolyte as depicted in Fig.6a exhibits discernible redox transitions irrespective of the scan rates. It can be stressed from the FTIR studies and from the results of other authors [74, 75] that the JFSC like any other biomass derived carbons contains various organic moieties that would interact with the electrolyte ions leading to interesting electrochemical picture. In a typical acid, the following interactions with the phenyl (-Ph) and alkyl (-R) groups were reported by $\mathrm{Hu}$ et al. [70] as,

$$
\begin{gathered}
\mathrm{O}=\mathrm{Ph}=\mathrm{O}+2 \mathrm{H}^{+}+2 \mathrm{e}^{-} \leftarrow \mathrm{HO}-\mathrm{Ph}-\mathrm{OH} ; \\
\mathrm{R}=\mathrm{O}+\mathrm{H}^{+}+\mathrm{e}^{-} \leftarrow \rightarrow \mathrm{R}-\mathrm{OH}
\end{gathered}
$$

Reversible quinone/hydroquinone transformation has been reported in acid electrolyte by several other authors also [76, 77]. These reactions are known to offer pseudo-Faradaic capacitance. Further, proton has the tendency to get adsorbed over the carbonyl groups on the JFSC due to the ind uced ion-dipole attraction. Consequently, the electric charge density gets changed adding to the double layer capacitance in the acid electrolyte [73].

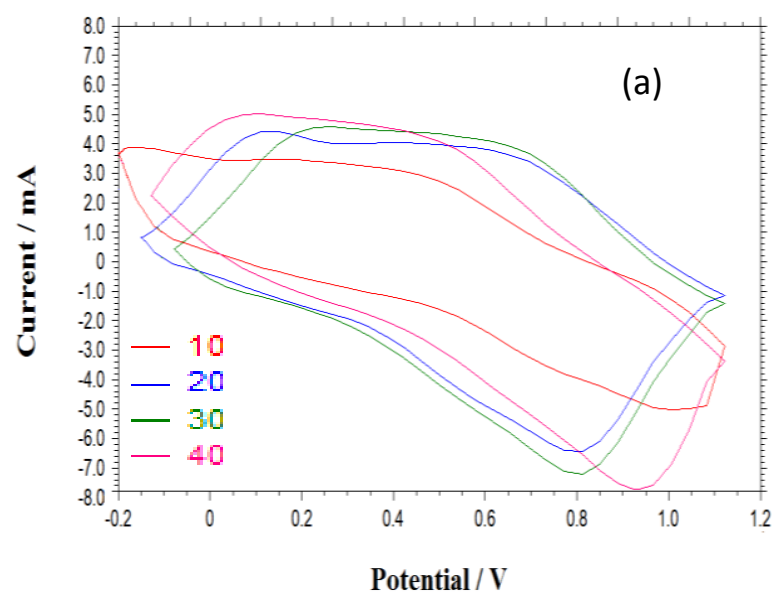

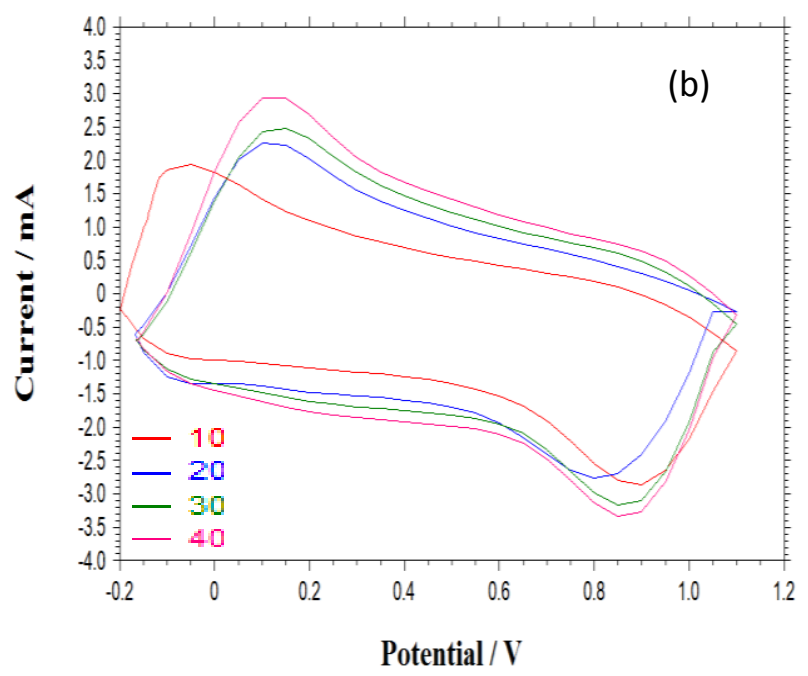

Fig $6 \mathrm{CV}$ of JFSC electrode in $1 \mathrm{M} \mathrm{H}_{2} \mathrm{SO}_{4}$ (a) and $1 \mathrm{M}$ $\mathrm{Na}_{2} \mathrm{SO}_{4}$ (b) at various scan rates $\left(\mathrm{mVs}^{-1} \mathrm{Vs} \mathrm{SCE}\right)$

Frackowiak et al. [78] concluded that the electrochemical behaviour of the carbon materials used as electrodes is related to their pore size and redox properties. Further, the above authors' electrochemical measurements showed a proportional increase of the specific capacitance with the nitrogen content in acid electrolyte medium and that the nitrogen content in the final product reflects its amount in the starting materials. Higher the amount of nitrogen higher is the basicity of the carbon surface (as evaluated by the values of $\mathrm{pH}_{\mathrm{PZC}}$ ). The above authors attributed to the enhancement in the capacitance values in the acidic medium by the following pseudo-Faradaic reactions [79].

$$
\begin{gathered}
\mathrm{C}^{*}=\mathrm{NH}+2 \mathrm{e}^{-}+2 \mathrm{H}^{+} \leftrightarrow \mathrm{C}^{*} \mathrm{H}-\mathrm{NH}_{2} \\
\mathrm{C}^{*}-\mathrm{NHOH}+2 \mathrm{e}^{-}+2 \mathrm{H}^{+} \leftrightarrow \mathrm{C}^{*}-\mathrm{NH}_{2}+\mathrm{H}_{2} \mathrm{O}
\end{gathered}
$$

Where $C^{*}$ stands for the carbon network. The same of kind of reactions are expected in the JFSC to conclude that capacitive currents and the total capacitance values has a contribution not only from the electric double layer charging but also from the pseudocapacitance of electroactive functional moieties significantly. This result is also corroborated again through impedance studies that the specific capacitance value in the acid is the highest.

It is reported that when the $\mathrm{pH}$ of the electrolyte is increased, the redox reactions involving surface quinone groups may become less important, but some other surface functionalities as pyrone-like groups can be active [80]. Though these reactions are not visible in our studies with JFSC at the scan rate investigated the above reasons may still be valid to explain the capacitance obtained. Few studies on the electrode cell performance of activated carbons in $\mathrm{Na}_{2} \mathrm{SO}_{4}$ show that the pseudo-Faradaic redox transitions of $\mathrm{O}$ and $\mathrm{N}$-containing electroactive surface groups are depressed in this electrolyte in comparison with $\mathrm{H}_{2} \mathrm{SO}_{4}[36,70,81-83]$. Nevertheless, Andreas and Conway [77] have indicated that the pseudo-capacitive contribution of surface oxygenated groups is negligible at neutral $\mathrm{pH}$ but Bichat et al. [71] have affirmed that pseudo-Faradaic 
reactions with seaweed derived carbon are possible in $0.5 \mathrm{M}$ $\mathrm{Na}_{2} \mathrm{SO}_{4}$ with adequate surface functionalities on the carbon surface. In the present study with JFSC also reversible redox peaks are observed and it is presumed that contribution from pseudo-capacitance may be expected in the neutral electrolyte medium also.

The results discussed above establish the complex interactions or influence of the electrolytes with $\mathrm{pH}$ and species involving cations and anions. Thus it is very difficult to provide insight on how the $\mathrm{pH}$ and the nature of the electrolytes influence the capacitive behavior of the carbon electrodes and research is invited in this direction. $\mathrm{Hu}$ et al's [70] work on $\mathrm{KOH}$-activated pistachio shells in $1 \mathrm{M}$ $\mathrm{NaNO}_{3}$ and $0.05 \mathrm{M} \mathrm{Na} \mathrm{SO}_{4}$ distinguishes fantastically the $\mathrm{CV}$ features and that the electrochemical reversibility in $1 \mathrm{M}$ $\mathrm{NaNO}_{3}$ was better than $\mathrm{Na}_{2} \mathrm{SO}_{4}$, though the mechanism of operation of these radicals has been explained by the adsorption ability.

Dependence of specific capacitance of JFSC electrode with scan rates and electrolyte medium is understood from Fig. 7. At $10 \mathrm{mVs}^{-1}$ scan rate, specific capacitance value as high as $316 \mathrm{Fg}^{-1}$ has been obtained in $1 \mathrm{M} \mathrm{H}_{2} \mathrm{SO}_{4}$ whereas it is 202 $\mathrm{Fg}^{-1}$ in $1 \mathrm{M} \mathrm{Na}_{2} \mathrm{SO}_{4}$. Despite the decrease in the capacitance JFSC has yielded appreciable capacity at lower scan rates. At $40 \mathrm{mVs}^{-1}$ rate, the delivered capacity in $1 \mathrm{M} \mathrm{H}_{2} \mathrm{SO}_{4}$ and $1 \mathrm{M} \mathrm{Na}_{2} \mathrm{SO}_{4}$ is 252 and $137 \mathrm{Fg}^{-1}$ respectively, which means that JFSC has retained $80 \%$ and $68 \%$ of the respective capacitance at $10 \mathrm{mVs}^{-1}$ rate in the electrolyte order mentioned. This value is comparable with the other biomass derived carbon electrodes reported [36, 69, 84]. Thus, jack fruit seeds being a zero-cost source and cost-effective nature might put JFSC as a prospective candidate for electrode material in electrochemical capacitors or pseudocapacitors.

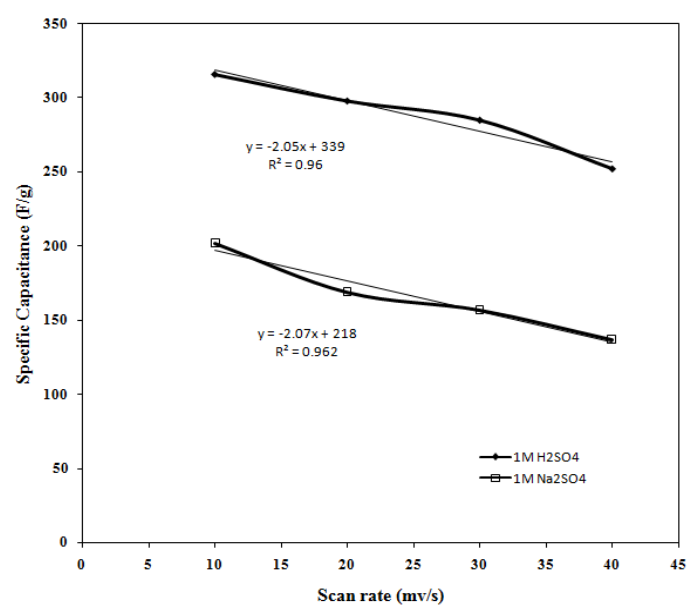

Fig 7 Dependence of specific capacitance of JFSC on scan rate

The corresponding maximum storage energy has been calculated as $87.8 \mathrm{Wh} \mathrm{kg}^{-1}$ in $\mathrm{H}_{2} \mathrm{SO}_{4}$ and $56.1 \mathrm{Whkg}^{-1}$ in $\mathrm{Na}_{2} \mathrm{SO}_{4}$ using the formula with $C V_{i}^{2}$ where $C$ is the specific capacitance (316 and $202 \mathrm{Fg}^{-1}$ respectively in the two medium) and $V_{i}$ is the initial voltage $(1.0 \mathrm{~V})$. As stated previously, the specific capacitance decreases with the scan rate. It is well known that for carbons, higher the capacitance, longer is the time required to acquire/release charges. The high specific capacitance that is observed at the lowest scan rate of $10 \mathrm{mVs}^{-1}$ may be attributed to the fact that the ions can diffuse into pores more easily (faster kinetic process) when the first cycle is completed [85]. The electrochemical storage in activated carbon electrodes has been explained by the electrical double layer theory and it is suggested that ions occupy the pores within the carbon to participate in the formation of the electrochemical double layer. So at higher scan rates when each cycle finishes quickly the ions cannot diffuse in to the pores as faster as the cycles are completed. Thus the poor performance at higher scan rates has been ascribed to [34].

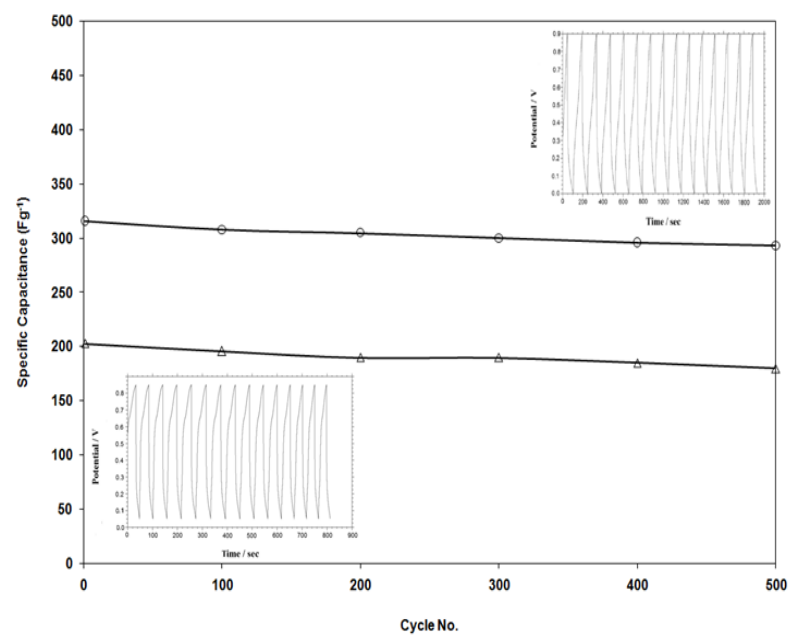

Fig. 8 Cycling performance of JSFC at $10 \mathrm{mV} \mathrm{s}^{-1}$ between 0.6 and $1.0 \mathrm{~V}$ in $1 \mathrm{M} \mathrm{H}_{2} \mathrm{SO}_{4}$ (a) and $1 \mathrm{M} \mathrm{Na}_{2} \mathrm{SO}_{4}$ (b). Inset shows the corresponding galvanostatic charge/discharge cycling behavior at $10 \mathrm{mAg}^{-1}$

Cycling performance of JSFC at $10 \mathrm{mVs}^{-1}$ between -0.6 and $1.0 \mathrm{~V}$ in $1 \mathrm{M} \mathrm{H}_{2} \mathrm{SO}_{4}$ and $1 \mathrm{M} \mathrm{Na}_{2} \mathrm{SO}_{4}$ is understood from Fig. $8 \mathrm{a}$ and $\mathrm{b}$. The inset in Fig. 8 shows the corresponding galvanostatic charge/discharge cycling behavior at $10 \mathrm{mAg}^{-1}$. For $\mathrm{CV}$ a wider potential range of -0.6 to $+1.0 \mathrm{~V}$ was selected to find the useful practical range for the chargedischarge of JFS based carbon electrodes at constant current and subsequently evaluated to be between 0.0 and $1.0 \mathrm{~V}$. Accordingly, inset in Fig. 8a and b shows the galvanostatic charge-discharge cycle profile (for the first 15 cycles) of JFSC electrodes in $1 \mathrm{M} \mathrm{H}_{2} \mathrm{SO}_{4}$ and $1 \mathrm{MNa}_{2} \mathrm{SO}_{4}$ respectively recorded in the range $0-1 \mathrm{~V}$ at a $10 \mathrm{mAg}^{-1}$.

The results of each galvanostatic charge-discharge measurement was similar and all curves exhibited isosceles triangular shape with the discharge time close to that of charge, reflecting high charge-discharge efficiency of the JFSC electrodes in two electrolyte medium. The difference of charge and discharge time influences the symmetric nature of the isosceles triangle. If the difference of charge and discharge time was less, then the isosceles triangle shape is more symmetric. The more symmetric the triangle, the higher will be the charge-discharge efficiency [86]. Although the triangles are similar, the information derived 
are different. We have seen that the area of the CV of JFSC in acid medium is broader when compared with the electrochemical features in neutral medium indicating that the capacitance of JFSC in acid medium would be higher. The reversible redox reactions of functional groups on the carbon surface occur to build up pseudocapacitance during charge-discharge processes and so the total capacitance is enhanced [86].

In general, capacitive behavior shows a strong dependence on the concentration of the electrolyte supported by the high surface area arising from the porous structure of the carbon. As explained from the results of $\mathrm{CV}$ studies because of the presence of $\mathrm{H}^{+}$ions as the mobile species in $\mathrm{H}_{2} \mathrm{SO}_{4}$ electrolyte better ionic diffusion in to the pores of the carbon is observed, resulting in an enhanced capacitive performance. Ultimately, the capacitive currents and hence the total capacitance values of JFSC has contributions mainly from pseudocapacitance of electroactive functional moieties in addition to double layer charging. From the galvanostatic charge-discharge studies, the gravimetric specific capacitance was calculated using the formula [36], $C\left(\mathrm{Fg}^{-1}\right)=i \Delta t / m \Delta V$, where $i$ is the current used for chargedischarge; $\Delta t$ is the time elapsed for the charge or discharge; $m$ is the mass of the active electrode and $\Delta V$ is the voltage interval of the charge or discharge. Specific capacitance calculated from the charge-discharge cycling studies at the end of the $5^{\text {th }}$ cycle has been evaluated to be $318 \mathrm{Fg}^{-1}$ and $211 \mathrm{Fg}^{-1}$ respectively in $1 \mathrm{M} \mathrm{H}_{2} \mathrm{SO}_{4}$ and $1 \mathrm{M} \mathrm{Na}_{2} \mathrm{SO}_{4}$, further presenting a stable performance at least up to 500 cycles in the acid as well as neutral medium as shown the Fig. 8 insets. The specific capacitance of JFSC electrode in $\mathrm{H}_{2} \mathrm{SO}_{4}$ medium is $316 \mathrm{Fg}^{-1}$ in the first cycle and $293 \mathrm{Fg}^{-1}$ after 500 cycles with $93 \%$ coloumbic efficiency while in $\mathrm{Na}_{2} \mathrm{SO}_{4}$ medium it is 203 and $180 \mathrm{Fg}^{-1}$ for the $1^{\text {st }}$ and $500^{\text {th }}$ cycle respectively exhibiting an efficiency of $87 \%$. The high charge-discharge efficiency of JFSC based electrodes indicates that electroactive carbon particles contacted well with electrolyte solution, or in other words the electrodes had a high hydrophilicity of their surface. Despite these advantages, the main disadvantage of the acid electrolyte is the high corrosion rate of the current collectors in actual capacitors. Here, both ion dissolution into the electrolyte combined with corrosion of the current collector will deteriorate the cycling performance of the capacitor [36]. Nevertheless, proper choice of hardware in the capacitor fabrication would tend to alleviate this drawback, leading to widespread application of acid based capacitors.

On investigating the JFSC performance in a neutral electrolyte such as $1 \mathrm{M} \mathrm{Na}_{2} \mathrm{SO}_{4}$, the specific capacitance is lower than the acid medium. The charge-discharge time is also reduced. The specific capacitance is mainly governed by the non-Faradic electrostatic sorption of ions at the double layer in the case of neutral electrolytes [87]. As the $\mathrm{H}^{+}$concentrations in neutral electrolyte are too low to induce gas evolution reactions [88], ions diffusing in to the pores of the carbon matrix are reduced and there would be only minimal chance of the bigger $\mathrm{SO}_{4}{ }^{2-}$ and $\mathrm{Na}^{+}$ions diffusion, resulting in lowered specific capacitance [89].
These results coincide with the observation of Swiatkowski et al. [90].

Centeno and Stoeckli [91] have published an excellent work on the specific double-layer capacitance of activated carbons in relation to their structural and chemical properties of various carbon varieties. Their studies provide an empirical correlation between the current density and the oxygen content of the carbon and with the capacitance. They have also suggested that $C_{\mathrm{o}}$, the limiting capacitance at a low current density of $1 \mathrm{mAcm}^{-2}$ of electrode surface, does not depend significantly on the oxygen content but the decrease of capacitance with increasing current density (of electrode surface) as a function of the oxygen content in the carbon seems to be valid and an empirical equation has also been proposed. It is apparent from the functional group analysis (FTIR spectroscopic) studies that the surface oxygen present in our JFSC may be distributed as acidic, phenolic and basic groups (carbonyl) and in order to prove the influence of the different oxygen-containing surface groups and electrochemical properties obviously requires additional study. Centeno and Stoeckli [91] suggest that the above correlation can be used as a tool to evaluate the performance of an unknown carbon for a capacitor. Studies involving enthalpies of immersion [92] and TPD [93] (temperature programmed desorption) would help with regards above.

It is interesting to note from the work of Centeno and Stoeckli [91] with 41 kinds of carbon and by Barranco et al. [94] on $\mathrm{KOH}$ activated carbon nanofibre (CNF) that the specific capacitance in $\mathrm{H}_{2} \mathrm{SO}_{4}$ depend not only on the total surface area area $S_{\text {tot }}$ (the sum of the micropore and external areas) and also on oxygen containing surface groups that desorb as $\mathrm{CO}$ from surface basic groups in TPD studies. A correlation between the specific capacitance and the $\mathrm{CO}$ contents at lower current densities has been proposed by Centeno and Stoeckli [91] and at higher current densities $\mathrm{CO}_{2}$ generating groups (acidic groups) also contribute to the total specific capacitance of the electrode materials. Barranco et al. [94] also state that the psuedocapacitance contribution is more for $\mathrm{H}_{2} \mathrm{SO}_{4}$ electrolyte. This observation matches with ours. Further activation with $\mathrm{KOH}$ had introduced additional micropores, high surface area and higher $\mathrm{CO}$ contents improving the specific capacitance but the amount of $\mathrm{CO}_{2}$ is not affected by $\mathrm{KOH}$ activation in their samples. It is to be recollected that JFSC, the subject material of ours has presented good pseudocapacitive behaviour, has been obtained without any chemical or physical activation and that does not prevent the application of the as-prepared JFSC as electrodes for capacitors.

Finally, it is to be mentioned that biomass precursors for preparing carbon electrodes for electrochemical capacitors is aplenty and hence a comparison of the capacitance values reported for those samples with our JFS derived carbon sample would weigh our sample for the intended application. A partial list of specific capacitance values (with their BET specific surface areas) reported for various biomass derived carbons including our samples has been provided in Table 2. Nevertheless, a complete review on the 
similar subject has been carried out by the present authors and has been published elsewhere [68].

Table 2 Comparison of specific capacitance and surface area of various biomass in different electrolytes

\begin{tabular}{|c|c|c|c|c|}
\hline $\begin{array}{c}\text { Biomass } \\
\text { Precursor }\end{array}$ & Electrolyte & $\begin{array}{c}\text { Specific } \\
\text { Capacitance }\left(\mathrm{Fg}^{-1}\right)\end{array}$ & $\begin{array}{l}\text { BET Surface } \\
\text { Area }\left(\mathrm{m}^{2} \mathrm{~g}^{-1}\right)\end{array}$ & Reference \# \\
\hline Cassava peel & $\mathrm{H}_{2} \mathrm{SO}_{4}$ & 153 & 1352 & 25 \\
\hline Bamboo & $\mathrm{Et}_{4} \mathrm{NBF}_{4}$ & 65 & 1413 & 33 \\
\hline Banana fiber & $\mathrm{Na}_{2} \mathrm{SO}_{4}$ & 74 & 686 & 36 \\
\hline $\begin{array}{l}\text { Sugar cane } \\
\text { bagasse }\end{array}$ & $\mathrm{H}_{2} \mathrm{SO}_{4}$ & 300 & 1788 & 38 \\
\hline Egg shell & $\begin{array}{c}\text { Acidic } \\
\text { Basic }\end{array}$ & $\begin{array}{l}284 \\
297\end{array}$ & 221 & 40 \\
\hline Fir wood & $\begin{array}{c}\mathrm{NaNO}_{3} \\
\mathrm{HNO}_{3} \\
\mathrm{H}_{2} \mathrm{SO}_{4}\end{array}$ & $\begin{array}{c}89 \\
120 \\
96\end{array}$ & 1016 & 69 \\
\hline $\begin{array}{l}\text { Pistachio } \\
\text { shell }\end{array}$ & $\begin{array}{l}\mathrm{H}_{2} \mathrm{SO}_{4} \\
\mathrm{NaNO}_{3}\end{array}$ & $\begin{array}{c}122 \\
81\end{array}$ & $1013-2145$ & 70 \\
\hline Seaweed & $\begin{array}{c}\mathrm{KOH} \\
\mathrm{H}_{2} \mathrm{SO}_{4} \\
\mathrm{Na}_{2} \mathrm{SO}_{4}\end{array}$ & $\begin{array}{l}201 \\
255 \\
125\end{array}$ & $750-1080$ & 71 \\
\hline Apple pulp & $\begin{array}{c}\mathrm{H}_{2} \mathrm{SO}_{4} \\
\mathrm{Et}_{4} \mathrm{NBF}_{4}\end{array}$ & $\begin{array}{l}232 \\
120\end{array}$ & 1200 & 95 \\
\hline $\begin{array}{l}\text { Jack fruit } \\
\text { seed carbon } \\
\text { (JFSC) }\end{array}$ & $\begin{array}{l}\mathrm{H}_{2} \mathrm{SO}_{4} \\
\mathrm{Na}_{2} \mathrm{SO}_{4}\end{array}$ & $\begin{array}{l}316 \\
203\end{array}$ & 932 & Present work \\
\hline
\end{tabular}

A comparison would show that our results are within the typical range reported by other researchers, indicating that JFSC proposed in the present study is applicable for electrochemical capacitors. Thus JFSC appears to be an attractive cost-effective substitute for commercial activated carbon as a pseudocapacitor electrode in acid as well as neutral medium.

\section{CONCLUSIONS}

The sphere of usefulness of biomass wastes for producing carbon materials has increased manifold in the recent times. Vegetable sources are gaining significance as hi-end products like carbon and activated carbon could be effectively produced from these zero-cost raw materials. The fact has been established through our results reported here by way of utilizing a household waste biomass. Carbon powder has successfully been produced by pyrolyzing the biomass of jack fruit seeds and has been electrochemically characterized for the possible application as electrode material for electrochemical capacitors (or pseudocapacitors). Performance of the biomass derived carbon has been completely evaluated in, $1 \mathrm{M} \mathrm{H}_{2} \mathrm{SO}_{4}$ and $1 \mathrm{M}$ $\mathrm{Na}_{2} \mathrm{SO}_{4}$ aqueous electrolytes. Studies show that the $\mathrm{pH}$ of the electrolytes influences both the capacitance values and electrochemical reversibility. Thus in $1 \mathrm{M} \mathrm{H}_{2} \mathrm{SO}_{4}, 316 \mathrm{Fg}^{-1}$ was the delivered capacitance while it is $203 \mathrm{Fg}^{-1}$ in $1 \mathrm{M}$ $\mathrm{Na}_{2} \mathrm{SO}_{4}$ at10 $\mathrm{mVs}^{-1}$ scan rate. The observed capacitance values has been attributed to the combination of pseudocapacitance and double layer charging coupled with physical properties and the surface organic functionalities on the biomass carbon with more of micropores in JFSC. The authors express through their studies that the carbons need not always be activated to give better (pseudo)capacitive performance. Nevertheless, control of mesopores and micropores in the carbon matrix through
$\mathrm{KOH}$ [95] or $\mathrm{ZnCl}_{2}$ activation [96, 97] may be one of the ways to realize enhancement in electrode performance.

The studies have also revealed the flexibility of jackfruit seeds as a good rated precursor for the preparation of electroactive carbon for making green technology viable. Its simple preparation process and the availability of the biomass in large scale might put JSFC as a prospective material for capacitor electrode applications. In addition to the excellent electrochemical features of JFSC, it is worthwhile to observe that the source for the carbon is renewable and natural, obviously cost effective. Thus the study opens up new doors in the search for new carbon materials for EDLC or pseudocapacitor applications. Finally it is relevant to consider the correlation that can exist between the jack varieties and its cultivation management for future developments in the technologically important area like energy. Although many uncertainties in understanding the mechanisms involved in electrochemical capacitors still remain, genuine progress continues to be made in the development of newer electrode materials. Consequently it is suggested that an intensified collaborative research is necessary to fully develop and tap the potential of electrochemical capacitors.

\section{ACKNOWLEDGEMENTS}

The authors thank The Management and The Principal of Thiagarajar College of Engineering and Madurai Kamaraj University, Madurai for the encouragement to carry out this fundamental research. The authors sincerely acknowledge the experts at various Institutes for characterizing our samples. A.A. expresses thankfulness to Prof. V. Eswaran (Late) for his encouragement and initial financial support received to meet characterization expenses.

\section{REFERENCES}

[1]. Parsons, R. The electrical double layer: recent experimental and theoretical developments, Chem. Rev., vol. 90, pp. 813-826, 1990.

[2]. Sarangapani, S., Lesener, P., Forchione, J., Griffith, A. and LaConti, A.B. Advanced double layer capacitors, J. Power Sources, vol. 29, pp. 355-364, 1990.

[3]. Conway, B.E. Electrochemical supercapacitors: scientific fundamentals and technological applications. Kluwer Plenum Press, New York, 1999.

[4]. Frackowiak, E. and Beguin, F. Carbon materials for the electrochemical storage of energy in capacitors, Carbon, vol.39, pp.937-950, 2001.

[5]. Pandolfo, A.G. and Hollenkamp, A.H. Carbon properties and their role in supercapacitors, J. Power Sources, vol.157, pp.11-27, 2006.

[6]. Simon, P. and Burke, A. Nanostructured Carbons: Double-Layer Capacitance and More, ECS Interface vol. 17, pp.38-43, 2008.

[7]. Beguin, F. and Frackowiak, E. Carbon Materials for Electrochemical Energy Storage Systems, CRC Press, 2009. [8]. Zhang, Y., Feng, H., Wu, X., Wang, L., Zhang, A., Xia, T., Dong, H., Li, X. and Zhang, L. Progress of 
electrochemical capacitor electrode materials: a review. Int. J. Hydrogen Energ., vol.34, pp.4889-4899, 2009.

[9]. Endo, M., Maeda, T., Takeda, T., Kim, Y.J., Koshiba, K., Hara, H. and Dresselhaus, M.S.J. Capacitance and PoreSize Distribution in Aqueous and Nonaqueous Electrolytes Using Various Activated Carbon Electrodes, J. Electrochem. Soc., vol.148, pp.A910-A914, 2001.

[10]. Qu, D. and Shi H. Studies of activated carbons used in double-layer capacitors, J. Power Sources, vol. 74, pp.99107, 1998.

[11]. Raymundo-Pinero, E., Kierzek, K., Machnikowski, J. and Beguin, F. Relationship between the nanoporous texture of activated carbons and their capacitance properties in different electrolytes, Carbon vol.44, pp.2498-2507, 2006.

[12]. Barbieri, O., Hahn, M., Herzog, A. and Kotz, R. Capacitance limits of high surface area activated carbons for double layer capacitors, Carbon, vol.43, pp.1303-1310, 2005.

[13]. Salitra, G., Soffer, A., Eliad, L., Cohen, Y. and Aurbach, D. Carbon Electrodes for Double- Layer Capacitors I. Relations Between Ion and Pore Dimensions, J. Electrochem. Soc., vol.147, pp.2486-2493, 2000.

[14]. Kierzek, K., Frackowiak, E., Lota, G., Gryglewicz, G. and Machnikowski, J.J. Electrochemical capacitors based on highly porous carbons prepared by $\mathrm{KOH}$ activation, Electrochim Acta vol.49, pp.515-523, 2004.

[15]. Fang, B. and Binder, L. Enhanced surface hydrophobisation for improved performance of carbon aerogel electrochemical capacitor, J. Power Sources, vol.163, pp.616-622, 2006.

[16]. Shiraishi, S., Kurihara, H., Okabe, K., Hulicova, D. and Oya, A. Electric double layer capacitance of highly pure single-walled carbon nanotubes (HiPco ${ }^{\mathrm{TM}}$ Buckytubes $^{\mathrm{TM}}$ ) in propylene carbonate electrolytes, Electrochem. Commun., vol.4, pp.593-598, 2002.

[17]. Barisci, J.N., Wallace, G.G. and Baughman, R.H. Electrochemical Characterization of Single- Walled Carbon Nanotube Electrodes, J. Electrochem. Soc., vol.147, pp.4580-4583, 2000.

[18]. Portet, C., Yang, Z., Korenblit, Y., Gogotsi, Y., Mokaya, R. and Yushin, G. Electrical Double-Layer Capacitance of Zeolite-Templated Carbon in Organic Electrolyte, J. Electrochem. Soc., vol.156, pp.A1-A6, 2009.

[19]. Lee, J., Kim, J. and Hyeon, T. Recent Progress in the Synthesis of Porous Carbon Materials, Adv. Mater., vol. 18, pp.2073-2094, 2006.

[20]. Morishita, T., Soneda, Y., Tsumura, T. and Inagaki, M. Preparation of porous carbons from thermoplastic precursors and their performance for electric double layer capacitors, Carbon, vol. 44, pp.2360-2367, 2006.

[21]. Morishita, T., Tsumura, T., Toyoda, M., Przepiorski, J., Morawski, A.W., Konno, H. and Inagaki, M, A review of the control of pore structure in MgO-templated nanoporous carbons, Carbon, vol.48, pp.2690-2707, 2010.

[22]. Xu, B., Wu, F., Chen, S., Zhang, C., Cao, G. and Yang, Y. Activated carbon fiber cloths as electrodes for high performance electric double layer capacitors, Electrochim. Acta, vol. 52, pp.4595-4598, 2007.
[23]. Qu, D. Studies of the activated carbons used in doublelayer supercapacitors, J. Power Sources, vol.109, pp.403$411,2002$.

[24]. Inagaki, M., Konno, H. and Tanaike, O. Carbon materials for electrochemical capacitors, J. Power Sources, vol.195, pp.7880-7903, 2010.

[25]. Ismanto, A.E., Wang, S., Soetaredjo, F.E. and Ismadji, S. Preparation of capacitor's electrode from cassava peel waste, Bioresour. Tech. vol.101, pp. 3534-3540, 2010.

[26]. Kotz, R. and Carlen, M. Principles and applicatons of electrochemical capacitors, Electrochim. Acta,vol.45, pp.2483-2498, 2000.

[27]. Leitner, K., Lerf, A., Winter, M., Besenhard, J.O., Villar-Rodil, S., Suarez-Garcia, F., Martinez-Alonso, A. and Tascon, J.M.D. Nomex-derived activated carbon fibers as electrode materials in carbon based supercapacitors, J. Power Sources, vol.153, pp.419-423, 2006.

[28]. Jurewicz, K., Babel, K., Ziolkowski, A. and Wachowska, H. Ammoxidation of active carbons for improvement of supercapacitor characteristics, Electrochim. Acta, vol. 48, pp. 1491-1498, 2003.

[29]. Li, W., Chen, D., Li, Z., Shi, Y., Wan, Y., Huang, J., Yang, J., Zhao, D. and Jiang, Z. Nitrogen enriched mesoporous carbon spheres obtained by a facile method and its application for electrochemical capacitor, Electrochem. Commun., vol.9, pp.569-573, 2007.

[30]. Shiraishi, S., Kibe, M., Yokoyama, T., Kurihara, H., Patel N, Oya A, Kaburagi, Y. and Hishiyama, Y. Electric Double Layer Capacitance of Multi-walled Carbon Nanotubes and B-doping Effect, Appl. Phys., vol.82, pp. 585-591, 2006.

[31]. Wang, D.W., Li, F., Chen, Z.G., Lu, G,Q. and Cheng, H.M. Synthesis and Electrochemical Property of BoronDoped Mesoporous Carbon in Supercapacitor, Chem. Mater., vol.20, pp.7195-7200, 2008.

[32]. Conway, B.E., Birss, V. and Wojtowicz, J. The role and utilization of pseudocapacitance for energy storage by supercapacitors, J. Power Sources, vol.66, pp.1-14, 1997.

[33]. Kim, Y.J., Lee, B.J., Suezaki, H., Chino, T., Abe, Y., Yanagiura, T., Park, K.C. and Endo, M. Preparation and characterization of bamboo-based activated carbons as electrode materials for electric double layer capacitors. Letters to the Editor / Carbon vol.44, pp.1592-1595, 2006. [34]. Jisha, M.R., Hwang, Y.J., Shin, J.S., Nahm, K.S., Prem Kumar, T., Karthikeyan, K., Dhanikaivelu, N., Kalpana, D., Renganathan, N.G. and Manuel Stephan, A. Electrochemical characterization of supercapacitors based on carbons derived from coffee shells, Mater. Chem. Phys., vol.115: pp.33-39, 2009.

[35]. Guo, Y., Qi, J., Jiang, Y., Yang, S., Wang, Z. and Xu, H. Performance of electrical double layer capacitors with porous carbons derived from rice husk, Mater. Chem. Phys. vol. 80, pp. 704-709, 2003.

[36]. Subramanian, V., Cheng, Luo., Stephan, A.M., Nahm, K.S., Sabu Thomas. and Wei, B.Q. Supercapacitors from Activated Carbon Derived from Banana Fibers, J. Phys. Chem. C, vol.111, pp.7527-7531, 2007.

[37]. Li, X., Han, C., Chen, X. and Shi, C. Preparation and performance of straw based activated carbon for 
supercapacitor in non-aqueous electrolytes, Micropor. Mesopor. Mater., vol.131, pp. 303-309, 2010.

[38]. Rufford, T.E., Jurcakova, D., Khosla, K., Zhu, Z. and Lu, G.Q. Microstructure and electrochemical double-layer capacitance of carbon electrodes prepared by zinc chloride activation of sugar cane bagasse, J. Power Sources, vol. 195, pp. 912-918, 2010.

[39]. Kalpana, D., Cho, S.H., Lee, S.B., Lee, Y.S., Rohit Misra, and Renganathan, N.G. Recycled waste paper-A new source of raw material for electric double-layer capacitors, J. Power Sources, vol.190, pp. 587-591, 2009.

[40]. Li, Z., Zhang, L., Amirkhiz, B.S., Xu, X.T.Z., Wang, H., Olsen, B.C., Holt, C.M.B. and Mitlin, D. Carbonized chicken eggshell membranes with 3D architectures as highperformance electrode materials for supercapacitors, Adv. Energ. Mater. vol. 2, pp. 431-437, 2012.

[41]. Prahas, D., Kartika, Y., Indraswati, N. and Ismadji, S.J. Activated carbon from jack peel waste: preparation, characterization and its application on methylene blue absorption, Environ. Protection Sci., vol. 2, pp. 1-10, 2006. [42]. Prahas, D., Kartika, Y. Indraswati, N. and Ismadji, S. Activated carbon from jackfruit peel waste by H3PO4 chemical activation: Pore structure and surface chemistry characterization, Chem. Engg., vol.140, pp. 32-42, 2008.

[43]. Kannan, N. and Veemaraj, T,J. Batch adsorption dynamics and equilibrium studies for the removal of cadmium (II) ions from aqueous solution using jack fruit seed and commercial activated carbons - a comparative study, Env. Agr. Food Chem., vol.9, pp.327-336, 2010.

[44]. Uddin Md. Tamez, Rukanuzzaman Khan Md, Maksudur ahman Islam Md, and Akhtarul Md. Jack fruit (Artocarpus heterophyllus) leaf powder: An effective adsorbent for removal of methylene blue from aqueous solutions, Indian J. Chem. Tech. vol.16, pp.142-149, 2009.

[45]. Peled, E., Eshkenazi, V. and Rosenberg, Y. Study of lithium insertion in hard carbon made from cotton wool, J. Power Sources, vol.76, pp.153-158,1998.

[46]. Cui, H., Cao, Y. and Pan W.P. Preparation of activated carbon for mercury capture from chicken waste and coal, Anal. Appl. Pyro. vol. 80, pp.319-324, 2007.

[47]. Kirubakaran, V., Sivaramakrishnan, V., Nalini, R., Sekar, T., Premalatha, M. and Subramanian, P. A review on gasification of biomass, Renew. Sust. Energ. Rev., vol.13, pp.179-186, 2009.

[48]. Katyal, S., Thambimuthu, K. and Valix, M. Carbonisation of bagasse in a fixed bed reactor: Influence of process variables on char yield and characteristics, Renew. Energ. vol. 28, pp. 713-725, 2003.

[49]. Eshkenazi, V., Peled, E., Burstein, L. and Golodnitsky, D. XPS analysis of the SEI formed on carbonaceous materials, Solid State Ionics, vol. 170, pp.83-91, 2004.

[50]. Lua, A.C. and Guo, J. Preparation and characterization of activated carbons from oil-palm stones for gas-phase adsorption, Colloids Surf. A Physicochem. Eng. Asp., vol. 179, pp.151-162, 2001.

[51]. Alcantara, R., Ortiz, G.F., Lavela, P. and Tirado, J.L. EPR, NMR, and electrochemical studies of surface-modified carbon microbeads, Chem. Mater., vol.18, pp.2293-2301, 2006.
[52]. Zhang, Y., Zhang, F., Li, G.D. and Chen, J.S. Microporous carbon derived from pinecone hull as anode material for lithium secondary batteries, Mater. Lett., vol.61, pp.5209-5212, 2007.

[53]. Dahn, J.R., Singh, A.K., Shi, H., Reimers, J.N., Zhong, Q. and Way, B.M. Dependence of the electrochemical intercalation of lithium in carbons on the crystal structure of the carbon, Electrochim. Acta, vol.38, pp. 1179-1191, 1993. [54]. Kyotani, T., Nagai, T., Inoue, S. and Tomita, A. Formation of new type of porous carbon by carbonization in zeolite nanochannels, Chem. Mater. vol.9, pp.609-615, 1997.

[55]. Cuesta, A., Dhamelincourt, P., Laureyns, J., MartínezAlonso, A. and Tascon, J.M.D. Comparative performance of X-ray diffraction and Raman microprobe techniques for the study of carbon materials. J. Mater. Chem. vol. 8, pp. 28752879, 1998.

[56]. Wang, Z., Lu, Z., Huang, Y., Xue, R., Huang, X. and Chen, L.J. Characterizations of crystalline structure and electrical properties of pyrolyzed polyfurfuryl alcohol, Appl. Phys. vol. 82, pp. 5705-5710,1997.

[57]. Inagaki, M. Pores in carbon materials-importance of their control, New Carbon Mater., vol.24, pp.193-232, 2009. [58]. Zhang, G.Q. and Zhang, S.T. Characterization and electrochemical applications of a carbon with high density of surface functional groups produced from beer yeast, J. Solid State Electrochem. vol.13, pp. 887-893, 2009.

[59]. Viswanathan, B., Neel, P.I. and Varadarajan, T.K. Method of Activation and Specific Application of Carbon Materials, 2009. (http://www.nccr.iitm.ac.in/e book-Carbon Materials final.pdf).

[60]. Hwang, Y.J., Jeong, S.K., Shin, J.S., Nahm, K.S. and Stephan, A.M. High capacity disordered carbons obtained from coconut shells as anode materials for lithium batteries, J. Alloys Compd. vol.448, pp. 141-147, 2007.

[61]. Webb, P.A. and Orr, C. Analytical Methods in Fine Particle Technology. Micromeritics Instrument Corp, Norcross, 1997.

[62]. Sing, K.S.W., Everett, D.H., Haul, R.A.W., Moscou, L., Pierotti, R.A., Rouquerol, J. and Siemieniewska, T. Reporting physisorption data for gas/solid systems with special reference to the determination of surface area and porosity, Pure Appl. Chem. vol.57, pp.603-619,1985.

[63]. Wibowo, N., Setiyadhi, L., Wibowo, D., Setiawan, J. and Ismadji, S. Adsorption of benzene and toluene from aqueous solutions onto activated carbon and its acid and heat treated forms: Influence of surface chemistry on adsorption, J. Hazard Mater. vol. 146, pp. 237-242, 2007.

[64]. Centeno, T.A. and Stoeckli, F. The role of textural characteristics and oxygen containing surface groups in the supercapacitor performance of activated carbons, Electrochim. Acta, vol.52, pp.560-566, 2006. [65]. Ho, C.C., Steingart, D.A., Evans, J.W. and Wright, P.K. Tailoring Electrochemical capacitor energy storage using direct write dispenser printing, ECS Trans. vol.16, pp.35-47, 2008.

[66] Garcia-Gomez, A., Miles, P., Centeno, T.A. and Rojo, J.M. Uniaxially oriented carbon monoliths as supercapacitor electrodes, Electrochim. Acta, vol.55,pp.8539-8544,2010. [67] Senthilkumar, S.T., Senthilkumar, B., Balaji, S., 
Sanjeeviraja, C. and Kalai Selvan, R. Preparation of activated carbon from sorghum pith and its structural and electrochemical properties, Mater. Res. Bull., vol.46,pp.413419, 2011.

[68]. Kalyani, P. and Anitha, A. Biomass carbon \& its prospects in electrochemical energy Systems, Int. J. Hydrogen Energ., vol. 38, pp. 4034-4045, 2013.

[69]. Wu F.C., Tseng R.L., Hu C.C. and Wang C.C. Physical and electrochemical characterization of activated carbons prepared from firwoods for supercapacitors, J. Power Sources, vol.138, pp.351-359, 2004.

[70]. Hu C.C., Wang C.C., Wu F.C. and Tseng R. L. Characterization of pistachio shell-derived carbons activated by a combination of $\mathrm{KOH}$ and $\mathrm{CO} 2$ for electric double-layer capacitors, Electrochim. Acta, vol. 52, pp. 2498-2505, 2007. [71]. Bichat, M.P., Raymundo-Pinero. E. and Beguin, F, High voltage supercapacitor built with seaweed carbons in neutral aqueous electrolyte, Carbon, vol. 48, pp. 4351-4361, 2010.

[72]. Wu, F.C., Tseng, R,L., Hu. C.C. and Wang, C.C. Effects of pore structure and electrolyte on the capacitive characteristics of steam- and $\mathrm{KOH}$-activated carbons for supercapacitors, J. Power Sources, vol. 144, pp. 302-309, 2005.

[73]. Bard, A. and Faulkner, L.R. Electrochemical Methods, Fundamentals and Applications. John-Wiley \& Sons, New York, 1980.

[74]. Hsieh, C.T. and Teng, H. Influence of oxygen treatment on electric double-layer capacitance of activated carbon fabrics, Carbon, vol. 40, pp. 667-674, 2002.

[75]. Frackowiak, E. Carbon materials for supercapacitor applications, Phys. Chem. Chem. Phys., vol.9,pp.1774-1785, 2007.

[76]. Raymundo-Pinero, E., Cadek, M. and Beguin, F. Tuning carbon materials for supercapacitors by direct pyrolysis of seaweeds, Adv. Funct. Mater. vol. 19, pp. 10321039, 2009.

[77]. Andreas, H.A. and Conway, B.E. Examination of the double-layer capacitance of a high specific-area C-cloth electrode as titrated from acidic to alkaline pHs, Electrochim. Acta, vol.51, pp. 6510-6520, 2006.

[78]. Frackowiak, E., Lota, G., Machnikowski, J., VixGuterl, C. and Beguin, F. Optimisation of supercapacitors using carbons with controlled nanotexture and nitrogen content, Electrochim. Acta, vol. 51, pp. 2209-2214, 2006.

[79]. Grimshaw, J. Electrochemical Reactions and Mechanisms in Organic Chemistry, Elsevier, Amsterdam, 2000.

[80]. Biniak, S., Swiatkowski, A. and Pakula, M. Electrochemical studies of phenomena at active carbonelectrolyte solution interfaces, Chemistry and physics of carbon, vol. 27, Dekker Inc, New York, pp. 125-225, 2001.

[81]. Qu, Q.T., Wang, B., Yang, L.C., Shi, Y., Tian, S. and Wu, Y.P. Study on electrochemical performance of activated carbon in aqueous $\mathrm{Li} 2 \mathrm{SO} 4, \mathrm{Na} 2 \mathrm{SO} 4$ and $\mathrm{K} 2 \mathrm{SO} 4$ electrolytes, Electrochem. Commun. vol.10, pp.1652-1655, 2008.

[82]. Konno, H., Ito, T., Ushiro, M., Fushimi, K. and Azumi, K. High capacitance $\mathrm{B} / \mathrm{C} / \mathrm{N}$ composites for capacitor electrodes synthesized by a simple method, J. Power Sources, vol.195, pp. 1739-1746, 2010.

[83]. Demarconnay, L., Raymundo-Pinero, E. and Beguin, F. A symmetric carbon/carbon supercapacitor operating at $1.6 \mathrm{~V}$ by using a neutral aqueous solution, Electrochem. Commun. vol.12, pp.1275-1278, 2010.

[84]. Taer, E., Deraman, M., Talib, I.A., Umar, A.A., Oyama, M. and Yunus, R.M. Physical, electrochemical and supercapacitive properties of activated carbon pellets from pre-carbonized rubber wood sawdust by $\mathrm{CO} 2$ activation, Curr. Appl. Phys. vol.10, pp.1071-1075, 2010.

[85]. Lust, E., Nurk, G., Janes, A., Arulepp, M., Nigu, P., Moller, P., Kallip, S. and Sammelselg, V. Electrochemical properties of nanoporous carbon electrodes in various nonaqueous electrolytes, J. Solid State Electrochem, vol.7, pp. 91-105, 2003.

[86]. Yafei, L., Zhonghua, H., Kun, X., Xiangwei, Z. and Qiang, G. Surface modification and performance of activated carbon electrode material, Acta Phys. Chim. Sin., vol. 24, pp.1143-1148, 2008.

[87]. Liu, Y., Xue, J.S. and Zheng, T. Mechanism of lithium insertion in hard carbons prepared by pyrolysis of epoxy resins, Carbon, vol.34, pp.193-200, 1996.

[88]. Hong, M.S., Lee, S.H. and Kim, S.W. Use of $\mathrm{KCl}$ aqueous electrolyte for $2 \mathrm{~V}$ manganese oxide/activated carbon hybrid capacitor, Electrochem. Solid State Lett. vol.5, pp. A227-A230, 2002.

[89]. Boehm, H.P. and Voll, M. Adsorption von sauren, Carbon, vol. 8, pp. 227-240, 1970.

[90]. Swiatkowski, A., Pakula, M. and Biniak, S. Cyclic voltammetric studies of chemically and electrochemically generated oxygen species on activated carbons, Electrochim. Acta, vol. 42, pp. 1441-1447, 1997.

[91]. Centeno, T.A. and Stoeckli, F. On the specific doublelayer capacitance of activated carbons, in relation to their structural and chemical properties, J. Power Sources, vol.154, pp. 314-320, 2006.

[92]. Stoeckli, F. and Lavanchy, A. The adsorption of water by active carbons, in relation to their chemical and structural properties, Carbon, vol. 38, pp. 475-494, 2000.

[93]. Carrasco-Marin, F., Mueden, A., Centeno, T.A., Stoeckli, F. and Moreno-Castilla, C. Water adsorption on activated carbons with different degrees of oxidation, J. Chem. Soc. Faraday Trans., vol.93, pp. 2211-2215, 1997.

[94]. Barranco, V., Lillo-Rodenas, M.A., Linares-Solano, A., Oya, A., Pico, F., Ibanez, J., Agullo-Rueda, F., Amarilla, J.M. and Rojo, J.M. Amorphous carbon nanofibers and their activated carbon nanofibers as supercapacitor Electrodes, J. Phys. Chem. C, vol.114, pp.10302-10307, 2010.

[95]. Centeno, T.A., Rubiera, F. and Stoeckli, F. Recycling of residues as precursors of carbons for supercapacitors; $1 \mathrm{st}$ Spanish National conference on advances in materials recycling and eco energy: Madrid, pp S04-S12, 2009.

[96]. Ahmadpour, A, and Do, D.D. The preparation of activated carbon from macadamia nutshell by chemical activation, Carbon, vol. 35, pp. 1723-1732,1997.

[97]. Molina-Sabio, M. and Rodriguez-Reinoso, F. Role of chemical activation in the development of carbon porosity. Colloids Surf. A Physchem. Eng. Aspects, vol. 241, pp.1525, 2004. 


\section{BIOGRAPHY}

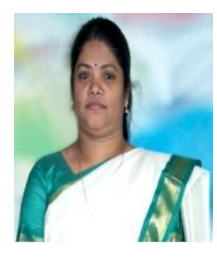

Dr. P. Kalyani, Asst. Professor, Department of Chemistry, DDE, Madurai Kamaraj University, Madurai. Email id: kalyani_1973@yahoo.com Specialization: Electrochemistry, Materials Synthesis, Batteries and Fuel cells, Biomass energy, Waste to Wealth Conversion.

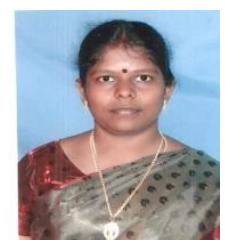

Mrs. A. Anitha, Asst. Professor, Department of Chemistry, SACS MAVMM Engineering College, Madurai. Email id: anitha.karuppasamy@gmail.com Specialization: Waste to Wealth Conversion. 